\title{
ABO Blood Groups and Malaria: Does it Really Matter?
}

\author{
Chandrika Rao*
}

Department of Pathology, K S Hegde Medical Academy Deralakatte, Mangalore, India

\begin{abstract}
Background: Malaria is most important parasitic disease affecting humans. The literature relating to malaria and the blood groups are sparse and have mixed response.

Objectives: The study was undertaken to assess the distribution of ABO blood group and their relationship with malaria species and parasite load.

Methods: In 200 malaria positive patients blood group analysis was done. Malaria parasite detection and load estimation was done using quantitative buffy coat (QBC) methodology using a fluorescent microscopy. ABO blood group was determined by agglutination test using antisera.

Results: A total of 200 were included in the study of which 121 cases were positive for plasmodium vivax, 32 cases were positive for plasmodium falciparum and 47 patients had mixed infection. The results of blood groups showed, 63 malaria infected patients with A blood group, 50 with B blood group, 80 with $\mathrm{O}$ blood group and 7 with $\mathrm{AB}$ blood group. Maximum parasite load was noted in blood group $\mathrm{O}$, followed by group A and B. The most common blood group infected with plasmodium vivax is blood group $\mathrm{O}$, similarly with $3+$ and $4+$ parasite load is blood group $\mathrm{O}$.
\end{abstract}

Conclusion: This study suggests significantly higher proportion of $\mathrm{O}$ blood group malaria patients infected with plasmodium vivax with higher parasite load.

Keywords: Malarial Parasites, ABO Blood Group, Malaria, Parasite Load

\section{Introduction}

Malaria is one of the most important parasitic disease affecting humans. Worldwide annually 8,81,000 deaths are related to malaria alone and in this India contributes a major share of incidence. According to WHO, in South East Asia region, 70\% of malaria cases are from India. Karnataka constitutes 28 districts. Out of which Dakshina Kannada contributes $50 \%$ of the cases to the state malaria profile. Hence it's a grave health problem that has tormented mankind for countless generations. ${ }^{[1]}$

Despite high mortality and morbidity, certain individuals living in malaria endemic regions appear relatively protected compared to those who suffer frequent severe malaria attacks. Resistance to malaria is dependant on the development of an immune response by the host and to a variable extent on certain innate characteristics possessing protective value against infection. These factors include Sickle cell trait and disease, ABO blood type and levels of glucose- 6- dehydrogenase. It is thought that understanding nature of relationship between $\mathrm{ABO}$ blood groups and malaria should provide an invaluable scourge in the window and such studies in population of malaria endemic regions will be helpful in elucidating any such relationship. ${ }^{[2]}$
There is paucity of hospital based, comparative studies to investigate the relationship between blood group types and malarial infection in our population where malaria is endemic. The objectives of present study were, to assess the distribution of ABO blood groups in malaria patients and its relationship with malaria species and parasite load.

\section{Materials and Methods}

The hospital based retrospective review of electronic medical records of malaria patients who attended outpatient or admitted with malaria in a tertiary care teaching hospital in Dakshina Kannada district of Karnataka. Totally 200 malaria positive cases were included in the study. The malaria parasite detection and load estimation was done using QBC methodology using fluorescent microscope. The parasite species was confirmed on peripheral smear. The parasite load on QBC was reported as $1+(<1$ parasite/HPF $), 2+(1-10$ parasites / HPF), 3+ ( 11-100 parasites /HPF) and 4+ ( $>100$ parasites /HPF).Commercial antisera was used for blood group determination ( tube method). Data analysis was done by Chi-Square test and $\mathrm{p}$ value of $<0.05$ was considered as statistically significant. 


\section{Result}

In our study malaria infection had male preponderance with $73.5 \%$ of the cases being males. Malaria affected all age groups and age ranged from 5- 82 years old. Out of 200 malaria positive patients $80(40 \%)$ had blood group $\mathrm{O}$ followed by $63(31.5 \%), 50(25 \%)$ and $7(3.5 \%)$ patients having blood group $\mathrm{A}, \mathrm{B}$ and $\mathrm{AB}$ respectively. (Table 1)(Figure 1).Among 200 patients, irrespective of blood group, Plasmodium vivax infection is seen in 121 $(60.5 \%)$, P. falciparum in $32(16 \%)$ and rest $47(23.5 \%)$ had mixed infection. Plasmodium vivax infected cases most commonly had blood group O (44.6\%), with statistical significant relationship $(\mathrm{p}=0.044)$ followed by blood group A $(30.5 \%)$, B (22.5\%). Out of total Plasmodium falciparum infected cases most common blood group was blood group A (34.3\%). Among the cases having mixed infection, most cases had blood group O (38.2\%) followed by $31.9 \%$ and $29.7 \%$ each of blood group A and B. (Table 1) (Figure2).

In $35 \%$ of the cases, parasite load was $2+$, followed by $30 \%, 22.5 \%, 11.5 \%$ with parasite load of $3+, 1+$ and $4+$ respectively. Out of the cases, that had parasite load of $1+, 38.2 \%$ had blood group O, 34\% and $25.5 \%$ cases had blood groups $\mathrm{A}$ and $\mathrm{B}$ respectively. Among cases with parasite load of $2+$, 37.1had blood group A, 30\%, 25.7\% and $7.1 \%$ had blood groups $\mathrm{O}, \mathrm{B}$ and $\mathrm{AB}$ respectively. Out of the cases that had parasite load of $3+, 51.6 \%$ had blood group $\mathrm{O}$, and $23.3 \%$ each of blood group A and B. Parasite load of $4+$ was seen in $43.4 \%, 30.4 \%$ and $26 \%$ had blood groups $\mathrm{O}, \mathrm{A}$ and $\mathrm{B}$ respectively. There was no statistical significance between blood group frequency and parasite load $(\mathrm{p}=0.321)$. (Table 2) (Figure 3$)$.

\section{Discussion}

Malaria has been known since antiquity. Much new information has emerged since relationship between $\mathrm{ABO}$ and malaria was first suggested $>40$ years ago. The observation by Miller et al that human erythrocytes lacking Duffy blood group antigens are refractory to invasion by Plasmodium vivax parasites indicates usefulness of studying the association of blood groups with malaria. In Indian scenario, the literature relating to malaria and the blood groups are sparse and have mixed results. ${ }^{[3]}$

Table 1: Distribution of cases

\begin{tabular}{|c|c|c|c|c|c|c|}
\hline & Blood group & A & B & O & AB & 12 \\
\hline \multirow{2}{*}{ Sex } & $\mathrm{M}$ & 45 & 38 & 59 & $57(73.5 \%)$ \\
\cline { 2 - 7 } & $\mathrm{F}$ & 18 & 12 & 21 & $53(26.5 \%)$ \\
\hline \multirow{2}{*}{ Type } & $\operatorname{Vivax}(\mathrm{V})$ & 37 & 27 & 54 & 3 & 4 \\
\cline { 2 - 7 } & Falciparum (F) & 11 & 9 & 8 & $32(16 \%)$ \\
\cline { 2 - 7 } & Mixed (M) & 15 & 1 & 18 & 0 & $47(23.5 \%)$ \\
\hline & & $63(31.5 \%)$ & $50(25 \%)$ & $80(40 \%)$ & $7(3.5 \%)$ & $200(100 \%)$ \\
\hline
\end{tabular}

Table 2: Parasite load vs blood group type

\begin{tabular}{|c|c|c|c|c|c|c|}
\hline \multicolumn{2}{|c|}{ Blood group } & A & B & O & AB & Total \\
\hline \multirow{2}{*}{ Parasite load in QBC } & $1+$ & $16(34 \%)$ & $12(25.5 \%)$ & $18(38.2 \%)$ & $1(2.1 \%)$ & $47(23.5 \%)$ \\
\cline { 2 - 8 } & $2+$ & $26(37.1 \%)$ & $18(25.7 \%)$ & $21(30 \%)$ & $5(7.1 \%)$ & $70(35 \%)$ \\
\cline { 2 - 8 } & $3+$ & $14(23.3 \%)$ & $14(23.3 \%)$ & $31(51.6 \%)$ & $1(1.6 \%)$ & $60(30 \%)$ \\
\cline { 2 - 8 } & $4+$ & $7(30.4 \%)$ & $6(26 \%)$ & $10(43.4 \%)$ & - & $23(11.5 \% 0$ \\
\hline
\end{tabular}

Table 3: Correlation of prevalence of malaria in different blood group

\begin{tabular}{|l|c|c|c|c|}
\hline Workers & A (\%) & B (\%) & O (\%) & AB (\%) \\
\hline Singh et al (2015) & 16.08 & 21.95 & 34.16 & 13.04 \\
\hline Gayathri et al (2013) & 16.09 & 40.09 & 35 & 1 \\
\hline Deepa et al (2011) & 22 & 42 & \\
\hline
\end{tabular}




\begin{tabular}{|c|c|c|c|c|}
\hline Workers & $A(\%)$ & B (\%) & $\mathrm{O}(\%)$ & $A B(\%)$ \\
\hline Otajevvo et al (2013) & 34.6 & 23.1 & 38.4 & 3.9 \\
\hline Sule Hussain et al (2014) & 32.3 & 35.3 & 17.7 & 24.2 \\
\hline Tewodros et al (2011) & 23.5 & 21.9 & 51.3 & 3.3 \\
\hline Present study & 31.5 & 25 & 40 & 3.5 \\
\hline
\end{tabular}

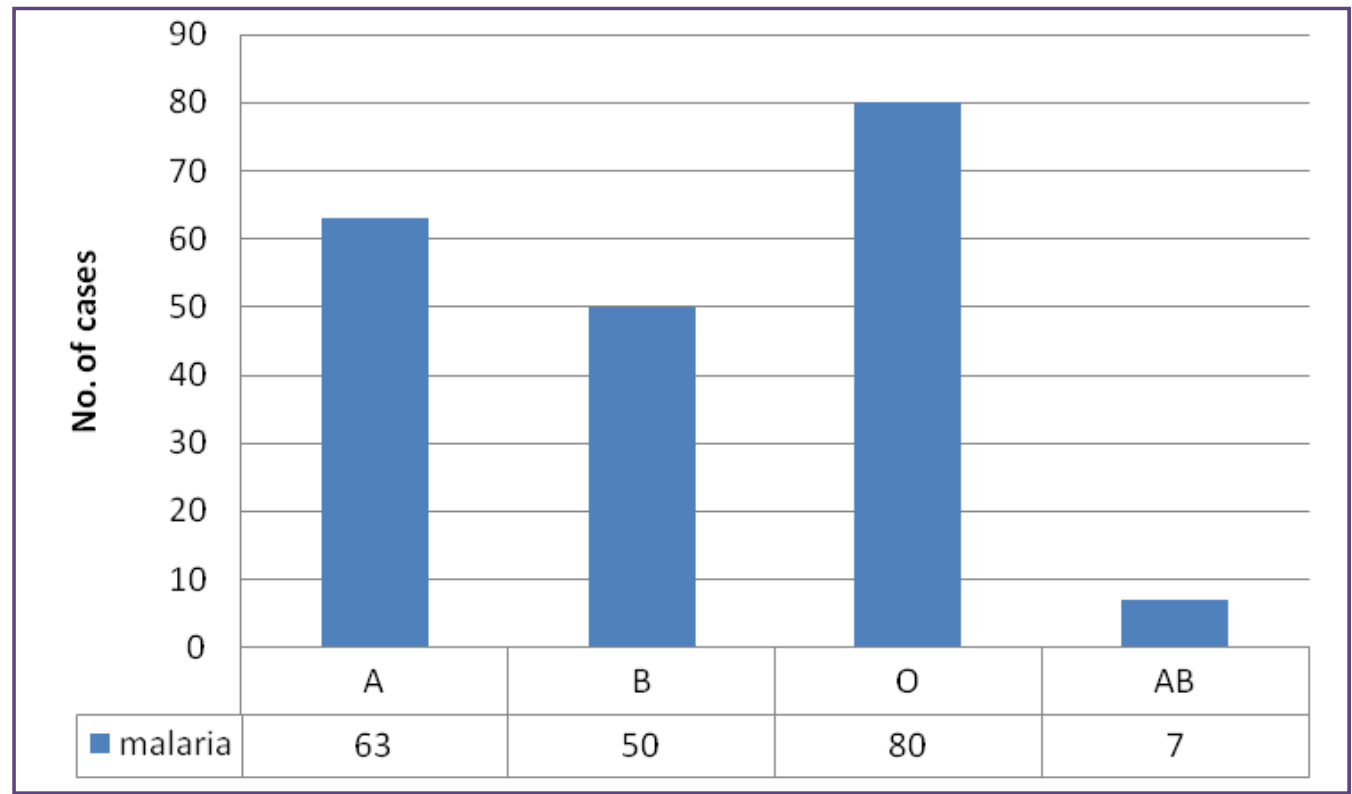

Fig. 1: Distribution of total cases according to blood groups

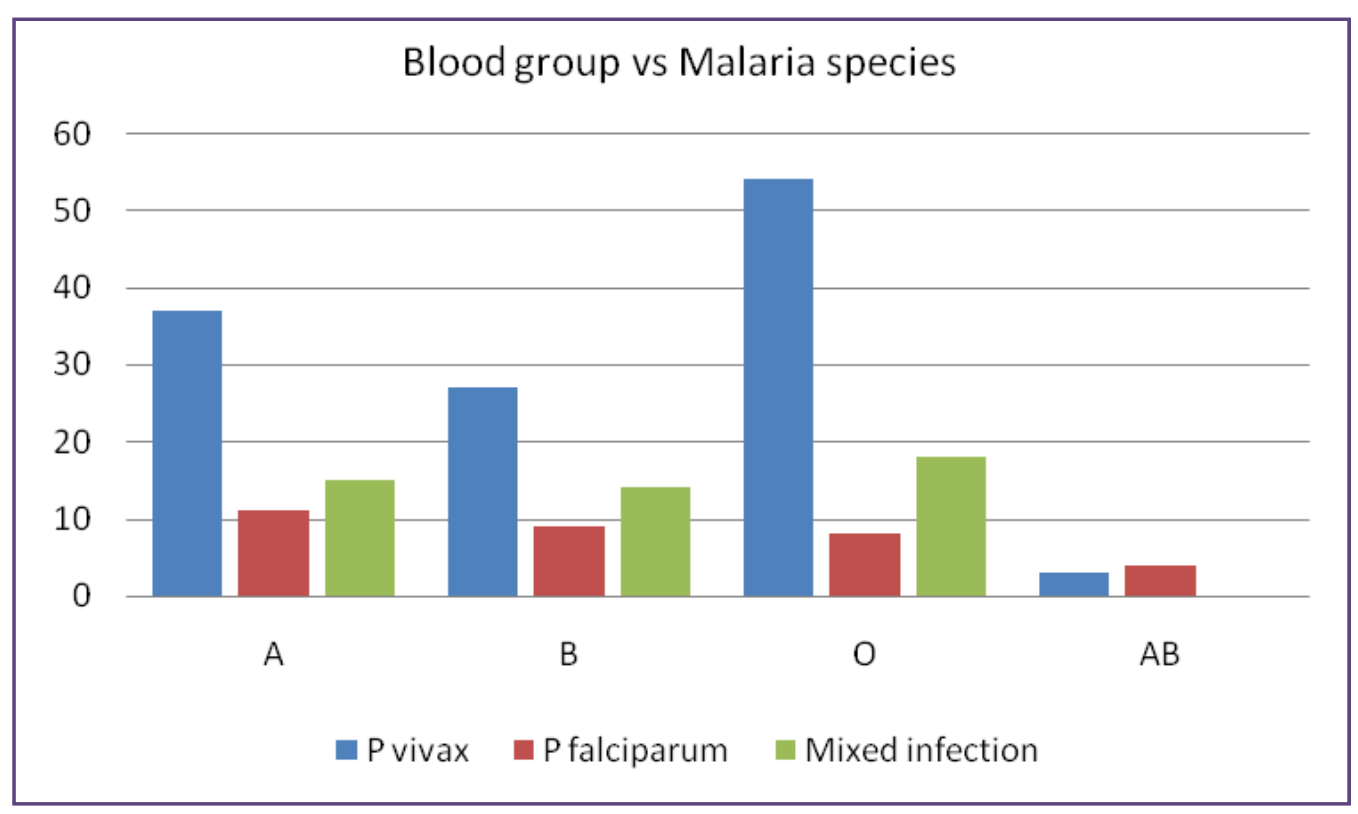

Fig. 2: Association between blood group and malaria species 


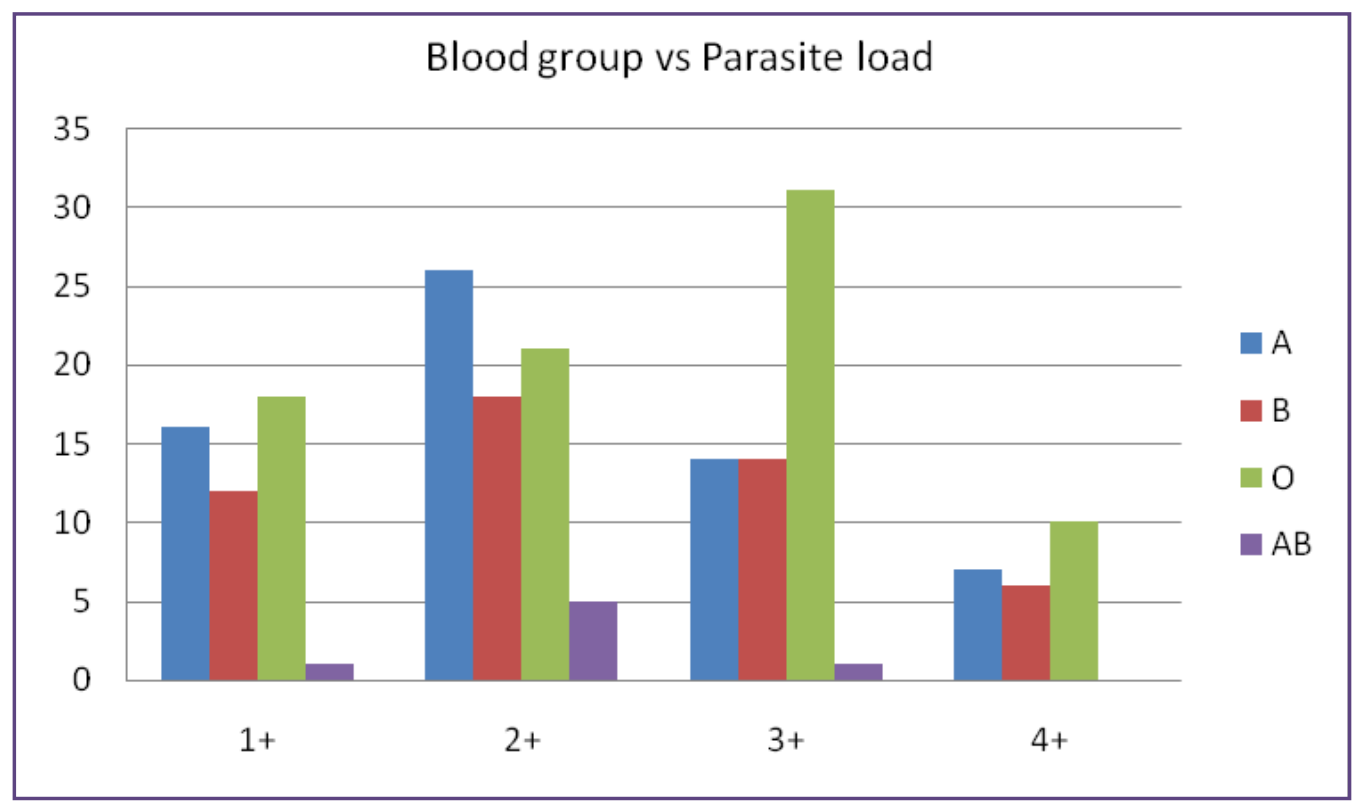

Fig. 3: Association of blood group and parasite load

In this study, high percentage of O blood group (40\%) phenotype was observed among the study participants followed by A ( $31.5 \%)$, B (25\%) and AB (3.5\%). This agrees with some previous studies that also reported high prevalence of blood group $\mathrm{O}$ phenotype in tropical regions where malaria is rampant. ${ }^{[4]}$

As regards to correlation there are some differences from other reports. High incidence of malaria in O blood group was found in the study of Singh et al, Tewodros et al, and Otejevvo et al. ${ }^{[2,4,5]}$ Gayatri et al, Sule Hussain et al and Deepa et al however reported higher incidence in B blood group $40.97 \%, 35.3 \%$ and $42 \%$ respectively. ${ }^{[3,6,7]}$ (Table 3)

According to the study conducted by our blood bank, most common blood group in our population is $\mathrm{O}$, followed by $\mathrm{B}$ and $\mathrm{A}$. Hence, highest number of malaria cases in blood group $\mathrm{O}$, could be explained by the fact that blood group $\mathrm{O}$ is the most prevalent blood group in our population and South India. ${ }^{[8,9]}$

In this study, higher proportion of individuals with blood group $\mathrm{A}$ and $\mathrm{B}$, were found to be infected with P. falciparum. This is also consistent with previous reports. ${ }^{[4,10,11]}$ Several mechanisms relate to these associations including affinity for anopheles species, impairment of merozoite penetration of RBCs, as well as cytoadherence, endothelial activation and rosetting activity. ${ }^{[4]}$

\section{Conclusion}

This study lends further credence to earlier related studies that in any given population, the highest number of subjects belongs to group $\mathrm{O}$, while the least number belong to $\mathrm{AB}$. The highest parasitemia rate was observed among group O. There was significant statistical relationship between blood group $\mathrm{O}$ being infected with $\mathrm{P}$ vivax $(\mathrm{p}=0.044)$ species. Since, blood group $\mathrm{O}$ is prevalent blood group in our population, this ostensibly implies that all ABO blood groups are equally at risk and therefore available malaria prophylactic and therapeutic strategies should be directed at individuals of all groups.

\section{Acknowledgements}

I acknowledge the support of Head of Department of Pathology and technical staff.

\section{Reference}

1. Kumar S, BV R, Kumar A, Mukhta A, Suman D, Navya V. Malarial trend in Dakshina Kannada, Karnataka: An epidemiological assessment from 2004 to 2013.Indian J Health Sci 2015;8:91-4.

2. Otajevvo FD. Prevalence of malaria parasitemia and its association with $\mathrm{ABO}$ blood grouping among students of Igbinedion university Okada, Nigeria. Br J Med Res 2013;3:1164-77.

3. Deepa, Vanamala A, Karuna R, Cecil R. ABO blood group and malaria related outcome. J vector borne Dis 48, March 2011:7-11.

4. Tewodros Z, Abraham D, Berhanu E. Association of ABO blood group and Plasmodium falciparum malaria in Dore Bafeno area, Southern Euthopia. Asian Pac J Trop Biomed 2011;1;289-294.

5. Singh G, Urhekar AD, Singh R. A study on correlation of malaria infection with A,B,O, RH blood group system. J Parasitol Vector Biol 2015;7:67-73. 
6. Gayathri BN, Harendra KML, Gomathi N, Jeevan S, Reethesh PP. Relationship between ABO blood groups and malaria with clinical outcome in rural area of South India. Glob J Med. Public Health 2013;2:1-7.

7. Sule HA, Idachaba SO, Idoko T. Susceptibility of humans of the ABO blood groups to $\mathrm{P}$ falciparum infection among patients attending Ahmadu Bello University clinic (Sickbay), Samaru-Zaria, Kaduna state, Nigeria. Sch J App Med Sci 2014;2:1305-9.

8. Sharanya H, Ruchi S, Shrijeet C, Lavnish O. Relationship between malaria and ABO blood group type. Int J Sci Res 2016;5:1041-44.
9. Chandrika R, Jayaprakash S. Frequency of ABO and Rhesus (D) blood groups in Dakshina Kannada district of Karnataka: A study from rural tertiary care teaching hospital in South India. NUJHS 2014;4:57-60.

10. Singh N, Shukla MM, Uniyal VP. ABO blood groups among malaria cases from district Mandla, Mandya Pradesh. Indian J Malariol 1995;32:59-63.

11. Fry AF, Griffiths MJ, Auburn S, Diakite M, Forton JT, Green A, et al. Common variations in the ABO glycosyltransferase is associated with susceptibility to severe Plasmodium falciparum malaria. Hum Mol Genet 2008; 17:567-76.

*Corresponding author:

Dr Chandrika Rao, Assistant professor and Blood Bank Officer, Department of Pathology, K S Hegde Medical

Academy Deralakatte, Mangalore, India

Phone: +91 8242204490

Email: chandrika_valal@yahoo.com

Date of Submission : 27.03.2017

Financial or other Competing Interests: None. 